\title{
A New Approach to the RP-HPLC Method for Simultaneous Estimation of Atorvastatin Calcium and Fenofibrate in Pharmaceutical Dosage Forms
}

\author{
S. D. BHINGE ${ }^{\text {* }}$, S. M. MALIPATIL ${ }^{\text {, A. AONDHALE }}$, R. HIRAVE ${ }^{\mathrm{c}}$, and A. S. SAVALI ${ }^{\mathrm{a}}$
}

${ }^{a}$ RMES's College of Pharmacy, Gulbarga.

${ }^{\mathrm{b}}$ HKES's College of Pharmacy, Gulbarga.

${ }^{\mathrm{c}}$ Sahyadri College of Pharmacy, Mathewad

somu1245@yahoo.co.in

Received 17 September 2011; Accepted 8 November 2011

\begin{abstract}
The present manuscript describes the development and validation of an isocratic reverse phase high-performance liquid chromatographic (RPHPLC) method for the estimation of Atorvastatin calcium and Fenofibrate in raw material and tablet. Atorvastatin Calcium, Fenofibrate and Diclofenac (internal standard) were well separated using a reversed phase column and mobile phase consisting of acetonitrile: $\mathrm{KH}_{2} \mathrm{PO}_{4}(50 \mathrm{mM})(72: 28 v / v)(\mathrm{pH} 4.1)$. The mobile phase was pumped at $1.0 \mathrm{~mL} / \mathrm{min}$ flow rate and atorvastatin calcium and fenofibrate were detected by UV-Vis detection at $260 \mathrm{~nm}$. The retention time for atorvastatin calcium, Internal Standard and fenofibrate were 4.34, 5.35 and $12.05 \mathrm{~min}$, respectively. The LOD and LOQ was found to be 1.95 and $4.80 \mu \mathrm{g} / \mathrm{mL}$ for atorvastatin calcium whereas for fenofibrate it was found to be 1.73 and $3.98 \mu \mathrm{g} / \mathrm{mL}$ in mobile phase. The developed method was validated by applying parameters as precision, accuracy, selectivity, reproducibility and system suitability tests.
\end{abstract}

Keywords: Reverse-phase high performance liquid chromatography, atorvastatin calcium, fenofibrate and diclofenac.

\section{Introduction}

Atorvastatin calcium ${ }^{1-4}$ (ATR) is ( $\beta$ R, $\delta$ R)-2-(4-fluorophenyl)- $\beta, \delta$-dihydroxy-5-(1-methyl ethyl)-3-phenyl-4-((phenyl amino)carbonyl)-1H-pyrrole-1-hepatonoic acid, a HMG CoA reductase inhibitor. Fenofibrate ${ }^{3-7}$ (FB) is 2-[4-(4-chlorobenzoyl)phenoxy]-2-methylpropanoic acid, 1-methylethyl ester, it is a lipid lowering agent. Literature survey reveals that, few HPLC and HPTLC methods have been reported for simultaneous estimation of ATR and FB as well as in combination with other drugs. N. Jain, et. al. ${ }^{6}$ has reported HPLC method for simultaneous estimation of ATR and FB using methanol: acetate buffer $\mathrm{pH} 3.7$ $(82: 18 \mathrm{v} / \mathrm{v})$ as eluting solvent. The methods reported by Jain and Kadav ${ }^{7}$ were excluding the internal standard, which was found to be the limitation of the method. Literature survey also revealed number of spectroscopic and RP-HPLC method development for both drugs in 
single component as well as in combination with other drugs ${ }^{5-22}$. The present work describes development of simple, precise and accurate isocratic reverse phase HPLC method for simultaneous estimation of ATR and FB in tablet formulation and same could be adapted for bioanalytical estimation of both drugs.

\section{Materials and Methods}

\section{Instrumentation}

Isocratic high pressure liquid chromatograph (Cyberlab-chrom-HPLC V 4.0) with LCP-100 pump, variable wavelength programmable UV/Vis detector LC-UV 100 and operating software cyberstore version no 4-0512-039 was used. The chromatographic separation carried out by reverse phase capcell pak C8 DDS5 column (4.6 mmLD x 250 $\mathrm{mm}$ i.d. particle size $5 \mu \mathrm{m}$. The mobile phase consisted a mixture of acetonitrile: $\mathrm{KH}_{2} \mathrm{PO}_{4}(72: 28 \mathrm{v} / \mathrm{v})(\mathrm{pH} 4.1)$ with a flow rate of $1.0 \mathrm{~mL} \mathrm{~min}{ }^{-1}$. The UV/Vis detector was set at a wavelength of $260 \mathrm{~nm}$. An injection volume of $10 \mu \mathrm{L}$ was used. Diclofinac was used as an internal standard.

\section{Chemicals}

Atorvastatin calcium (Emcure Pharmaceutical, Pune), Fenofibrate (Smruthi Organics, Solapur), Diclofinac (Emcure Pharmaceutical, Pune), HPLC grade acetonitrile for chromatography was procured from Merck Chemical Division Ltd., Mumbai. All other chemicals were of analytical reagent grade quality. Doubly distilled water was used to prepare mobile phase solutions.

\section{Standard Solutions}

Standard stock solutions of atorvastatin calcium, fenofibrate and IS were prepared separately by dissolving $10 \mathrm{mg}$ atorvastatin calcium, $10 \mathrm{mg}$ fenofibrate and $10 \mathrm{mg}$ IS, respectively, in $10 \mathrm{~mL}$ methanol to obtain a final concentration of $1 \mathrm{mg} / \mathrm{mL}$. The concentration of atorvastatin calcium and fenofibrate was varied in the range of 5$25 \mu \mathrm{g} / \mathrm{mL}$ and the concentration of IS was maintained at a constant level of $100 \mu \mathrm{g} / \mathrm{mL}$. All of the subsequent dilutions for working standards were made with methanol. Twenty microlitres of the standard solutions were injected separately and chromatogram was recorded. The stock and working solutions were stored at $+4^{\circ} \mathrm{C}$.

\section{Preparation of Tablet Formulations}

Ten tablets were accurately weighed and crushed to fine powder. Four accurately weighed quantities of the powder, equivalent to $10 \mathrm{mg}$ of ATR and $160 \mathrm{mg}$ of FB were taken in different $10 \mathrm{~mL}$ volumetric flasks and used for the assay. The solution was magnetically stirred for $10 \mathrm{~min}$ after addition of methanol. The resulting solution was centrifuged at 5,000g. Appropriate solutions were prepared by taking suitable aliquots of clear filtrate and IS solution, diluting with methanol to obtain final solution. The amount of ATR and FB per tablet was calculated from the related linear regression equation.

\section{Assay Validation}

The method was validated according to ICH guidelines and USP 24 requirements of analytical procedures 23, 24. Assay validation involved determination of linearity, selectivity, accuracy, precision, limit of detection (LOD) and limit of quantification (LOQ). Intra-day and inter-day precision values were estimated at two different concentrations of ATR and FB five times on the same day and on three separate days to obtain the relative standard deviation (\%RSD). Several approaches are given in ICH 
guidelines to determine the detection (LOD) and quantification (LOQ) limits. In this study, LOD and LOQ were based on the standard deviation of the response and the slope of the corresponding calibration curve using the equations ${ }^{25}, 26$. Analytic interferences from endogenous substances were investigated by recovery test.

The parameters tested for system suitability included asymmetry factor, tailing, theoretical plates, retention time.

System suitability tests are an integral part of HPLC method development. It can be defined as tests to ensure that the method can generate results of acceptable accuracy and precision. The requirements for system suitability are usually developed after method development and validation have been completed. The criteria selected are based on the actual performance of the method, as determined during its validation. These parameters include relative standard deviation (\%RSD) of retention times, tailing factor, asymmetry factor and theoretical plate for repetitive injections. Precision and accuracy can often be enhanced by the use of an appropriate IS for HPLC method, which also serves to correct fluctuations in the detector response. When added prior to sample preparation, a properly chosen IS can be used to correct sample losses. The IS is a different compound from the analyte but one that is well resolved in the separation. However, it was chosen as the IS because it showed a shorter retention time with better peak shape and better resolution, compared with other potential internal standard compounds.

\section{Recovery Studies}

To keep an additional check on the accuracy and selectivity of the developed assay method, recovery experiments were performed by adding known amounts of pure drug to pre-analyzed samples of tablets. The percent recovery was calculated by comparing the concentration obtained from spiked samples with the actual added concentration. Thus, the effect of common formulation excipients on chromatograms was investigated. The known amounts of ATR, FB and a constant level of IS were added to tablet dosage forms and the mixtures were analyzed by the proposed method. The recovery results were calculated using calibration equations after five repeated experiments.

\section{Result and Discussion}

In the present study, chromatography of ATR and FB was investigated on a C8 column. To develop a rugged and suitable HPLC method for the quantitative determination of ATR and FB, different mobile phase compositions and ratios were employed. Our preliminary trials using different compositions of mobile phases consisting of water and acetonitrile in different ratios did not give good peak shape. Introduction of $\mathrm{KH}_{2} \mathrm{PO}_{4}$ buffer $(50 \mathrm{mM})$ instead of water improved the peak shape of ATR and FB. From these preliminary studies, the mobile phase acetonitrile: $\mathrm{KH}_{2} \mathrm{PO}_{4}(50 \mathrm{mM})(72: 28)(v / v)($ at $\mathrm{pH} 4.1$ ) was found to be the most suitable carrier, and the flow rate was also determined to be $1.0 \mathrm{~mL} / \mathrm{min}$ for HPLC analysis. Isocratic delivery of the mobile phase was preferred, as gradient elution requires control by a gradient HPLC pump system, long re-equilibration time, perfect solvent mixing, etc. Analyses were performed at $25^{\circ} \mathrm{C}$, as less reproducibility in ATR and FB retention time was observed at lower temperatures. The retention times were varied between 4.339- 4.494 min for ATR and 11.902-12.910 min for FB in all media. For ATR, FB and IS, sharp and symmetrical single peaks were obtained with good resolution using above conditions.

The USP suggests that system suitability tests could be performed prior to analysis $^{24}$. Typically, at least two of these criteria are required to demonstrate system suitability for the proposed method. Some of the tests were carried out on freshly prepared standard solutions including drug compound and IS. Tailing factors were 1.33 
for ATR, 1.12 for FB and 1.49 for IS. The theoretical plate number $(N)$ was 6280.75 for ATR, 12253.38 for FB and 8316.01 for IS. The chromatographic conditions described ensured adequate retention and resolution for drug compound. The retention times of drug ATR, FB and IS were 4.34, 12.05 and $5.35 \mathrm{~min}$, respectively (Figure 1). Asymmetry was 1.30 for ATR, 1.20 for FB and 1.32 for IS. The variation in retention time for five replicate injections of drug compound and IS gave an RSD of $0.10 \%$ for ATR, $0.20 \%$ for FB and $0.10 \%$ for the IS. The results obtained from the system suitability tests (Table 1) satisfy the USP and ICH guidelines.

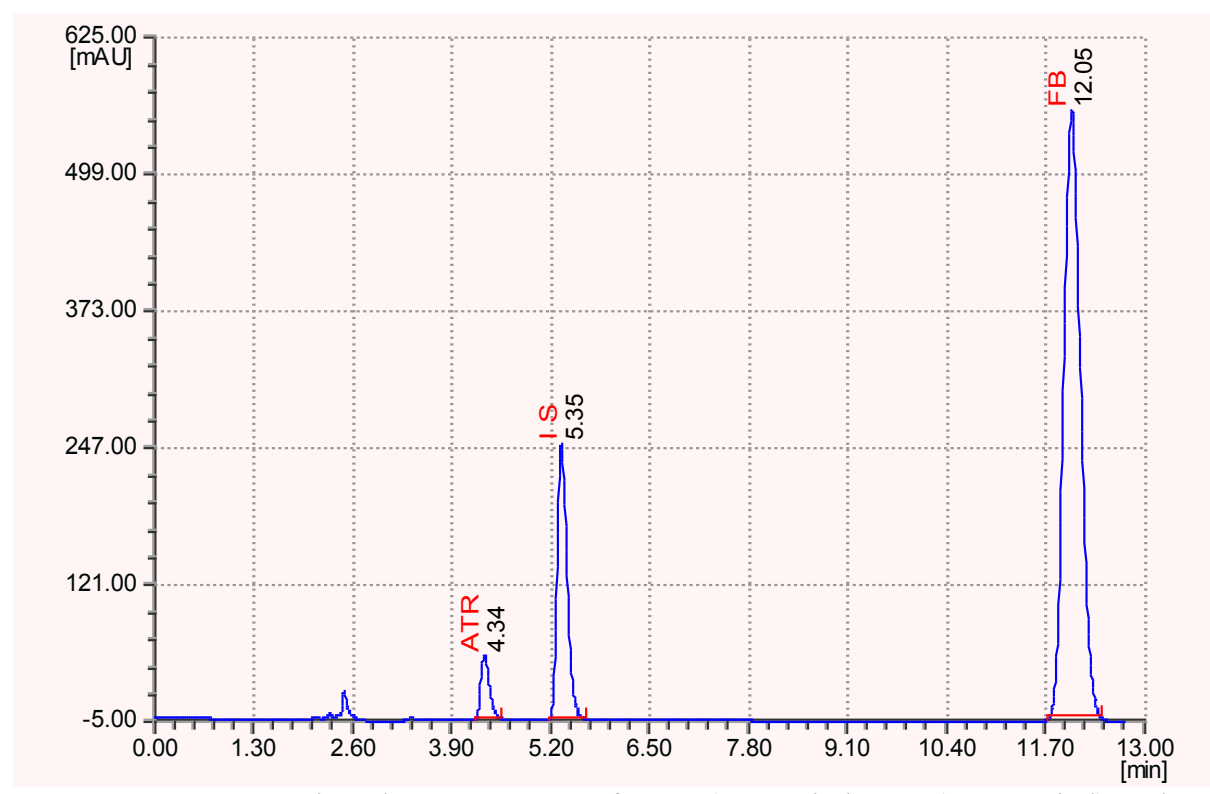

Figure 1: Representative chromatograms of ATR $(10 \mu \mathrm{g} / \mathrm{ml}), \mathrm{FB}(160 \mu \mathrm{g} / \mathrm{ml})$ and IS.

Table 1: System Suitability Test parameter for ATR, FB and IS ( $\mathrm{n}=5)$.

\begin{tabular}{cccc}
\hline Parameter & ATR & FB & IS \\
\hline $\begin{array}{c}\text { Retention Time } \\
\text { (min) } \pm \text { \%RD }\end{array}$ & $4.34 \pm 0.10$ & $12.05 \pm 0.20$ & $5.35 \pm 0.10$ \\
$\begin{array}{c}\text { Tailing Factor } \pm \\
\text { \%RSD }\end{array}$ & $1.33 \pm 0.18$ & $1.12 \pm 0.14$ & $1.49 \pm 0.13$ \\
$\begin{array}{c}\text { Thorotical Plates } \pm \\
\text { \%RSD }\end{array}$ & $6280.75 \pm 0.88$ & $12252.38 \pm 0.95$ & $8316.01 \pm 0.96$ \\
$\begin{array}{c}\text { Asymmetry } \pm \\
\text { \%RSD }\end{array}$ & $1.30 \pm 0.10$ & $1.20 \pm 0.18$ & $1.32 \pm 0.13$ \\
\hline
\end{tabular}

The calibration curves for ATR in mobile phase were drawn by plotting the peak area ratio of ATR to IS versus concentration of ATR, and yielded the correlation coefficient $(r)$ of 0.992 over the concentration range $5-25 \mu \mathrm{g} / \mathrm{mL}$. The calibration curves for FB in mobile phase were drawn by plotting the peak area ratio of FB to IS versus concentration of $\mathrm{FB}$, and yielded the correlation coefficient $(r)$ of 0.991 over the 
concentration range 5-25 $\mu \mathrm{g} / \mathrm{mL}$. Values obtained for the calibration curve and their related validation parameters are presented in Table 2.

Table 2: Characteristics of the linear regression analysis of ATR and FB.

\begin{tabular}{ccc}
\hline & ATR & FB \\
\hline Linearity range $(\mu \mathrm{g} / \mathrm{mL})$ & $5-25$ & $5-25$ \\
Slope & 2472.4 & 3103.99 \\
Intercept & -1324.2 & 14982.48 \\
Correlation coefficient $(r)$ & 0.992 & 0.991 \\
Detection limit $(\mu \mathrm{g} / \mathrm{mL})$ & 1.95 & 1.73 \\
Quantification limit $(\mu \mathrm{g} / \mathrm{mL})$ & 4.80 & 3.98 \\
\hline
\end{tabular}

Resolution was always good in the linearity range studied. LOD for ATR and FB was $1.95,1.73 \mu \mathrm{g} / \mathrm{mL}$ and LOQ for ATR and FB sample was $4.80,3.98 \mu \mathrm{g} / \mathrm{mL}$ (Table 2).

The stability of the reference substance and sample solutions was checked by analyzing a prepared standard solution of ATR and FB in methanol aged at $+4{ }^{\circ} \mathrm{C}$ in the dark, against a sample freshly prepared. The results demonstrated that the working reference solutions were stable up to 5 days. The ATR and FB area ratio to IS for the assay reference solutions over 5 days did not change considerably.

The developed method was validated according to the standard procedures and the results obtained are tabulated in Table 3. Accuracy, precision and reproducibility of the proposed method were assessed by performing replicate analysis of the standard solutions. Within calibration curves, two different concentrations were prepared and assayed with related calibration curves to determine Inter-day and Intra-days variability. The Inter-day and Intra-days (for three consecutive days) precision, accuracy, and reproducibility were determined as the \%RSD, mean value (Table 3). These results indicate that the method developed achieves a high degree of precision, accuracy and reproducibility.

When working on standard solutions, and according to the obtained validation parameters, results encourage the use of the proposed method described for the assay of ATR and FB in raw material, pharmaceutical dosage forms and for bioanalytical studies.

The results obtained from the analysis of tablet dosage forms are summarized in Table 4. To prove the absence of interference by excipients, recovery studies were carried out using the standard addition method. Recovery experiments were carried out after known amount of the pure drug was added. Recovery experiments using the developed assay procedure further indicated the absence of interference from commonly encountered pharmaceutical excipients used in the selected formulation (Table 4). LIPICURE-TG tablet contains active ingredients, atorvastatin calcium and microionised fenofibrate, along with following inactive ingredients: Titanium dioxide and yellow oxide of iron. 
Table 3: Inter-day and Intra-days precision of ATR \& FB standards.

\section{Theoretical concentration $\left(\mu \mathrm{g} \mathrm{mL} \mathbf{L}^{-1}\right)$}

\begin{tabular}{|c|c|c|c|c|c|c|c|c|}
\hline & \multicolumn{2}{|c|}{$\begin{array}{c}\text { Inter-day } \\
\text { measured } \\
\text { concentration }\end{array}$} & \multicolumn{2}{|c|}{$\begin{array}{l}\text { Intra-days } \\
\text { measured } \\
\text { concentration }^{\mathrm{a}}\end{array}$} & \multicolumn{2}{|c|}{$\begin{array}{l}\text { Inter-day } \\
\text { measured } \\
\text { concentration }\end{array}$} & \multicolumn{2}{|c|}{$\begin{array}{l}\text { Intra-days } \\
\text { measured } \\
\text { concentrationa }\end{array}$} \\
\hline & Mean $^{\mathrm{b}}$ & $\begin{array}{l}\text { RSD } \\
\%\end{array}$ & Mean $^{\mathrm{b}}$ & $\begin{array}{l}\text { RSD } \\
\%\end{array}$ & Mean $^{\mathrm{b}}$ & $\begin{array}{l}\text { RSD } \\
\%\end{array}$ & Mean $^{\mathrm{b}}$ & $\begin{array}{l}\text { RSD } \\
\%\end{array}$ \\
\hline 8 & 7.91 & 1.57 & 7.78 & 0.95 & 8.04 & 0.84 & 7.80 & 1.01 \\
\hline 32 & 31.94 & 0.39 & 31.79 & 0.05 & 31.98 & 1.33 & 31.78 & 0.06 \\
\hline
\end{tabular}

${ }^{\mathrm{a}}$ Intra-days reproducibility was determined from five different runs for three consecutive days.

${ }^{\mathrm{b}}$ Mean values represent five different ATR \& FB standards for each concentration.

The developed method is easy to perform, sensitive, reproducible, enough to determine ATR and FB in aqueous samples and biological fluids.

Table 4: Results of the assay and the recovery analysis of ATR and FB in tablet samples.

\begin{tabular}{lcc}
\hline & ATR & FB \\
\hline Labeled claim Tablet (mg/tablets) & 10 & 160 \\
Mean of amount found & & 161.89 \\
\%RSD of amount found & 10.45 & 0.19 \\
Added & 1.75 & 32 \\
Recovered & 2 & 32.11 \\
\%Recovery & 2.05 & 100.34 \\
\% RSD of recovery & 102.5 & 0.28
\end{tabular}

${ }^{a}$ Each value is the mean of five experiments.

${ }^{\mathrm{b}}$ Each value is the mean of five experiments.

\section{Conclusion}

The proposed RP-HPLC method is accurate, precise, rapid and selective for the simultaneous determination of atorvastatin calcium and fenofibrate in raw material and tablet dosage form by external standardization method. The assay results, recoveries in tablets were in good agreement with their respective label claims and added standard 
sample. The results also suggested non-interference of formulation excipients in the estimation. Hence it could be conveniently adapted for the routine quantitative estimation of drugs from biological fluids and quality control analysis.

\section{References}

1. Budavari S. The Merck Index. $12^{\text {th }}$ ed.; Whitehouse station (NI); Merck and Co. Inc.; 1996.

2. Gennaro A E, Remington's The science and practice of pharmacy $20^{\text {th }}$ ed.; Easton (PA); Merck publishing Co; 2000; Vol 2.

3. Indian Pharmacopeia, Govt of India Ministry of health and family welfare; Controller of Publications, Delhi; 2007, vol II, 249.

4. British Pharmacopoeia. Indian edition, 2008, Vol, 891.

5. Nagraj K, Mashru R and Kalamkar V, Anal Sci. 2007, 23, 445.

6. Jain N, Jain D. and Raghuwanshi R, Ind. J of Pharm Sci. 2008, 70(2), 263.

7. Kadav A and Vora D, J of Pharm and biomed anal. 2008, 48(1), 120.

8. Nakarani N V, Bhatt K K, Patel R D and Bhatt H S, J of AOAC Int. 2007, 90(3), 700.

9. Deepan T and Ambethkar P K, Euro. J. of Appl. Scie. 2011, 3(2) 35.

10. Erturk S, Sevinc A E, Ersoy L and Ficicioglu S, J. Pharm. Biomed. Anal. 2003, 33, 1017.

11. Zahid Z, Farooqui M N, Mangle A A and Nikalge A G, Afri. J of Pharm \& Pharmacol. 2008, 2(10), 204.

12. Stanisz B and Kania L, Acta Poloniae Pharma - Drug Resea 2006, 63(6), 471.

13. Zzaman M T, Khan S A, Arora A and Ahmad O, Electron J. Biomed. 2009, 3, 41.

14. Shah D A, Bhatt K K, Mehata R S, Shankar M B, Baldania S L and Gandhi T R, Ind. J Pharm Sci. 2007, 69(4), 546.

15. Shah D A, Bhatt K K, Mehata R S, Baldania S L and Gandhi T R, Ind. J Pharm Sci. 2008, 70(6), 754.

16. Shah D A, Bhatt K K, Mehata R S, Shankar M B, Baldania S L and Gandhi T R, Ind. $J$ Pharm Sci. 2007, 69(4), 701.

17. Mishra P, Shah K and Gupta A, Ind. J of Pharm Sci. 2007, 69(6), 831.

18. Panchal H J, Suhagia B N, Patel N J and Rathod I S, Chromato. 2009, 69, 91

19. Mohammadi A, Rezanour N, Dogaheh M A, Bidhorbed F G, Hashem M and Walker R, J. Chromatogr. B. 2007, 846, 215.

20. Qutab S S, Razzaq S N, Khan I U, Ashfaq M and Shuya Z A, J. Food and Drug Anal. 2007, 15, 139.

21. Sultana N, Arayne S M, Shah N S, Shafi N and Naveed S, J Chin Chem Soc. 2010, 57(6), 1.

22. El-gindy A, Emara S, Masbah M K and Hadad G M, II Farma. 2005 60, 425.

23. ICH, Topic Q2A, Validation of analytical procedures: methodology.PMP/ICH/281/95.

24. The United States Pharmacopoeia. 24th revision, Easton; Rand Mc Nally Taunton; 2000.

25. Riley $\mathrm{C}$ M and Rosanske $\mathrm{T} \mathrm{W}$, Development and validation of analytical methods. Elsevier; New York; 1996.

26. Swartz M E and Krull I S, Analytical method development and validation. Marcel Dekker, New York; 1997. 


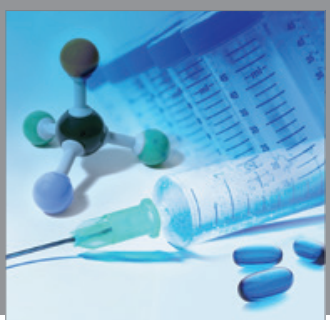

International Journal of

Medicinal Chemistry

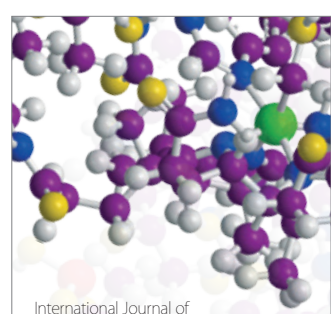

Carbohydrate Chemistry

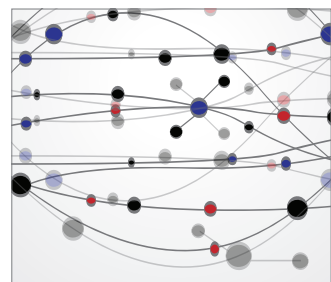

The Scientific World Journal
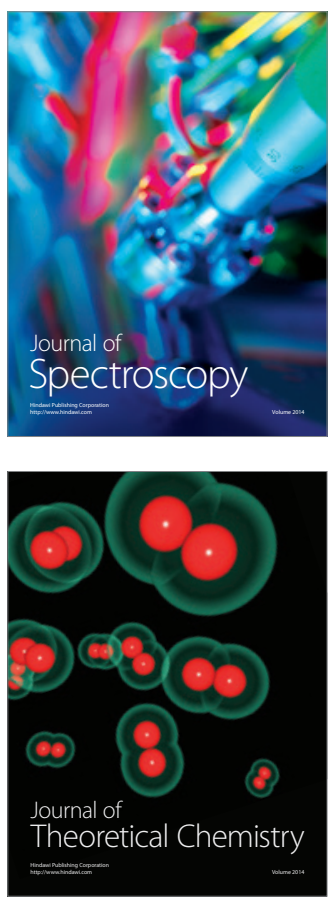
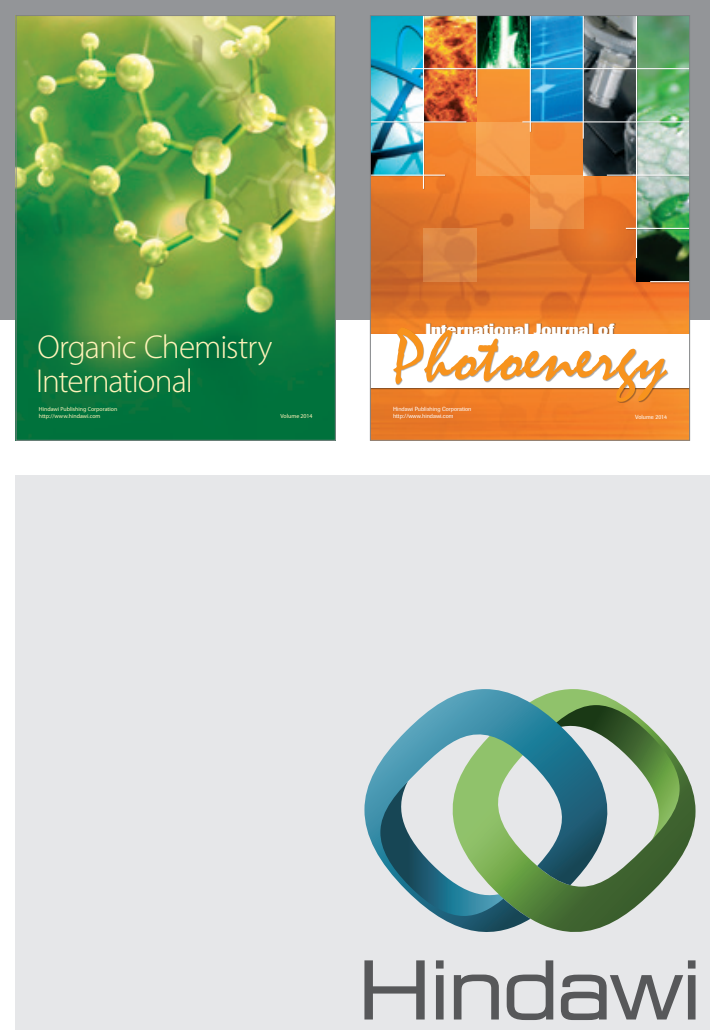

Submit your manuscripts at

http://www.hindawi.com
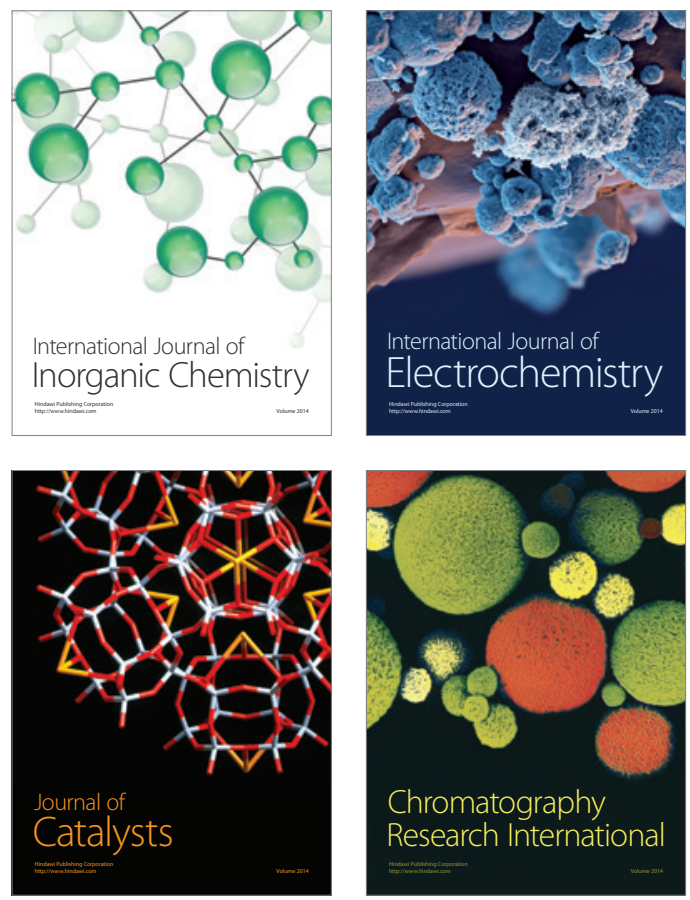
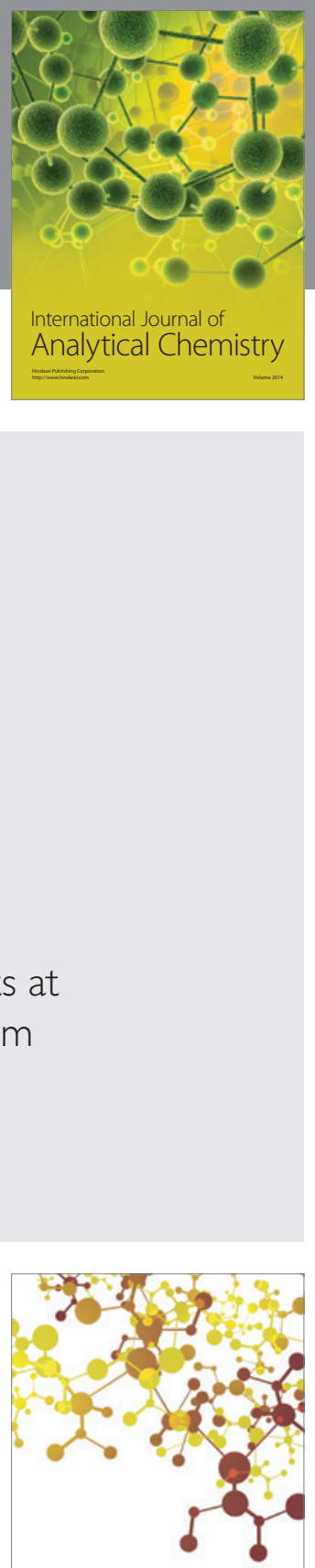

Journal of

Applied Chemistry
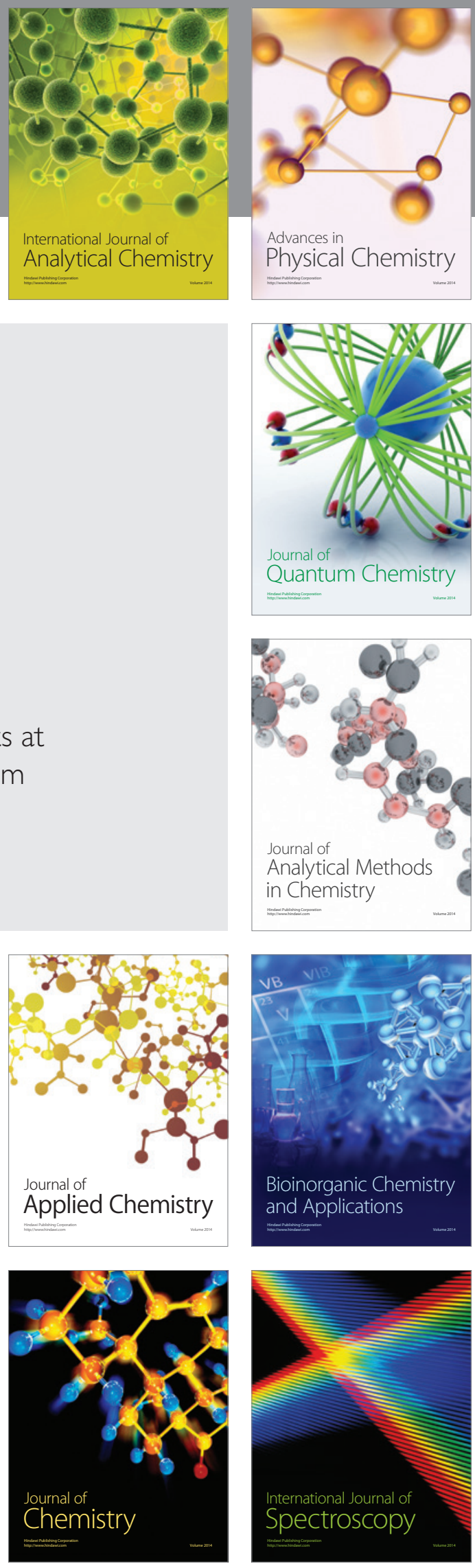